\title{
A critical examination of substoichiometric isotope dilution analysis using thymidine and leucine*
}

\author{
David F. BIRD \\ Département des sciences biologiques, Université du Québec à Montréal. C.P. 8888, Succ. Centre-ville. \\ Montréal, Qc. Canada H3C 3P8
}

\begin{abstract}
SUMMARY: Isotope dilution analysis is used to determine the specific activity of radiolabelled precursors such as ${ }^{3} \mathrm{H}-$ thymidine and ${ }^{3} \mathrm{H}$-leucine incorporated into DNA or protein in environmental samples. However, it is shown theoretically, experimentally, and using the results of published studies that the method can be misleading when one of its many requirements is not met. First, on the basis of our current understanding of thymidine metabolism, it is not only possible, but probable, that endogenous thymidine synthesis will not remain constant at different concentrations of external thymidine addition. Changes in the rate of thymidine biosynthesis will significantly bias the results of the standard analysis. Yet it is very difficult or impossible to know whether changes have occurred in any particular case. Second, published results show evidence of stimulation of total thymidine incorporation rate at higher thymidine concentrations. These changes in incorporation rate will also bias the conclusions drawn from the assay. Third, impurities common to heavily labelled precursors can produce misleading results. Finally, the current statistical methodology of isotope dilution experiments can be greatly improved with little or no extra effort. It is suggested that, if possible, isotopes should be used empirically to derive conversion factors based on incubations; theoretical calculations based on isotope dilution experiments are not always trustworthy.
\end{abstract}

Key words: Substoichiometric isotope dilution analysis, bacterial production, thymidine, leucine

\section{INTRODUCTION}

Bacterial growth rate assays based on radiolabelled thymidine (Fuhrman and Azam, 1982) and radiolabelled leucine incorporation (Kirchman et al., 1985) are the most commonly used methods for growth estimates of the heterotrophic bacteria in situ. In order to use biochemical theory-based calculations to extrapolate from radiochemical incorporation rate to growth rate using this method, it is necessary to know the specific activity of the thymidine nucleotide, or leucine, precursor pool (cf. Findlay et al., 1984; Moriarty, 1986; Simon and Azam, 1989). When labelled thymidine is added in great enough

\footnotetext{
*Received August 31, 1998. Accepted November 4, 1998.
}

concentration, bacterial synthesis of thymidine may be completely inhibited. It is claimed that the disappearance of native nucleotide synthesis removes the major diluting factor in most environments (Moriarty, 1988), so that one may use the specific activity of the added radioactive thymidine directly in calculations.

It is difficult to know beforehand the appropriate concentration to use for any particular environment. Simon and Azam (1989) have recommended using an isotope dilution factor of 2 to account for de novo synthesis of leucine. A prerequisite of this method is that unlabelled leucine concentration in the sample will be measured with HPLC in order to account for extracellular dilution, a procedure that does not lend itself to routine (only three laboratories worldwide have carried out the procedure, to my knowledge). 
The solution to this problem has been either to assume that a standard concentration recommended in the literature is sufficient to block de novo production and that extracellular dilution is negligible, or else to measure the specific activity of the labelled precursor pool directly using isotope dilution analysis (Forsdyke, 1968).

The thymidine additions recommended in the literature are not guaranteed to remove interference from precursor dilution, however. Recommended concentrations increased in value with time as a wider range of environments was sampled (cf. Fuhrman and Azam, 1982 (5 nM); Riemann et al., 1982 (10 nM); Moriarty, $1986(20 \mathrm{nM}))$, yet even the highest of the recommended levels has been found insufficient on occasion. For example, Bell (1986) found that greater than $35 \mathrm{nM}$ TdR was required to maximize incorporation in the Swedish lake Sormogen. Findlay et al. (1984) found that TdR concentrations as high as $55 \mathrm{nM}$ were insufficient to eliminate precursor dilution in blackwater river samples, and eutrophic lakes may contain substantial extracellular thymidine (Chróst, 1990).

Leucine concentrations recommended for the measurement of bacterial production have also increased with time. Simon and Azam (1989) recommended $2 \mathrm{nM}$ leucine. Jorgensen (1992) advised using $100 \mathrm{nM}$, or even $200 \mathrm{nM}$ in very rich environments, with evidence that a residual $5-10 \%$ of leucine biosynthesis is not suppressed even then. Van Looij and Riemann (1993) also recommended more than $200 \mathrm{nM}$ estracellular leucine in eutrophic water. Chróst (1990) found 10 to $40 \mathrm{nM}$ leucine in 2 eutrophic lakes, quantities that varied by up to $200 \%$ throughout a $24 \mathrm{hr}$ period.

The alternative to accepting recommended levels of addition is to estimate isotope dilution directly. This note presents a closer examination of the assumptions implicit in isotope dilution analysis. Calculations and examples from the literature demonstrate weaknesses of the method for environmental samples.

\section{STANDARD ANALYTICAL PROCEDURE}

The standard procedure is based on the assumption that labelled precursors (thymidine will henceforth be used as an example) will be incorporated into DNA in proportion to their abundance relative to unlabelled sources. That is, using the notation of Findlay et al. (1984):

$$
\mathrm{C}_{\mathrm{obs}} / \mathrm{C}_{\max }=\mathrm{L} /(\mathrm{L}+\mathrm{P}+\mathrm{A})
$$

where $\mathrm{C}_{\text {obs }}$ is observed radioactivity incorporated in a sample, $\mathrm{C}_{\text {max }}$ is the quantity of radioactivity that would be incorporated if labelled thymidine were the only source available to the bacteria (i.e., if $\mathrm{P}$ were 0 ), $\mathrm{L}$ is the constant concentration of labelled thymidine added, $\mathrm{P}$ is the unknown pool or pools (exogenous and endogenous) of thymidine naturally available to the bacteria for incorporation into DNA, and $\mathrm{A}$ is the amount of unlabelled thymidine added in graded amounts to a series of samples. This equation is inverted and rearranged to yield a linear equation:

$1 / \mathrm{C}_{\mathrm{obs}}=(\mathrm{L}+\mathrm{P}) /\left(\mathrm{L} \cdot \mathrm{C}_{\text {max }}\right)+\left(1 /\left(\mathrm{L} \cdot \mathrm{C}_{\text {max }}\right)\right) \cdot \mathrm{A}$

In this form, the equation is analysed by linear regression (Moriarty and Pollard, 1981; Findlay et al., 1984; Bell, 1986). The X intercept, calculated as the ratio of ( $\mathrm{Y}$ intercept / slope), equals $-(\mathrm{L}+\mathrm{P})$. Because $\mathrm{L}$ is known, the 'degree of participation' (DP) of labelled thymidine can be calculated as:

$\mathrm{DP}=\mathrm{L} /(\mathrm{L}+\mathrm{P})=\mathrm{L} \cdot$ slope $/ \mathrm{Y}$ intercept

In the method presented by Moriarty and Pollard (1981), the potential radioactivity incorporated $\left(\mathrm{C}_{\max }\right)$ and thus the total thymidine incorporation during the incubation period (TTI) is then calculated:

$$
\begin{gathered}
\mathrm{C}_{\text {max }}=\mathrm{C}_{0} / \mathrm{DP} \\
\mathrm{TTI}=\mathrm{C}_{\text {max }} / \mathrm{SA}
\end{gathered}
$$

where $\mathrm{C}_{0}$ is the incorporation of radioactivity from labelled Tdr (of concentration L) during a non-diluted productivity incubation, DP is degree of participation as above, and SA is the specific activity of the labelled thymidine. $\mathrm{C}_{0}$ can be from a separate incubation, or from the undiluted sample of the dilution experiment. The same estimate can be derived more directly (with greater accuracy: see 'Statistical considerations' below) using only the slope of the linear dilution equation. In order to show the similarity between this approach and the standard one, I introduce a "diluting factor" (DF):

$\mathrm{C}_{\max }=1 /(\mathrm{L} \cdot$ slope) (within the experiment) $=\mathrm{C}_{0} / \mathrm{DF}$ (for samples outside the experiment) (6), $\mathrm{DF}=\mathrm{C}_{\text {obs }} / \mathrm{C}_{\max }$ Then TTI $=\mathrm{C}_{\max }^{\max } / \mathrm{SA}$. 
$\mathrm{DF}$ is calculated from the results of the experiment using $\mathrm{C}_{\text {obs }}$, which in this case is the radioactivity incorporated in the absence of additional cold thymidine. TTI is then transformed into bacterial production as outlined in Bell (1993).

\section{FIRST ASSUMPTION: \\ CONSTANT INTRACELLULAR SYNTHESIS}

The standard analysis depends absolutely on the assumption that $\mathrm{P}$, the pool of naturally available thymidine diluting the added label, remains constant despite changes in added cold thymidine. Bell (1986) suggested that, rather than remaining constant, when levels of added thymidine exceed a threshold amount, $\mathrm{P}$ declines in intracellular pools due to repression of thymidine synthesis by thymidylate synthetase. When thymidine concentration is sufficient to inhibit synthesis, then the intercept will be reduced. Rather than changing the slope, when de novo production of thymidine has been blocked, the initial slope of the relationship between $1 / \mathrm{C}_{\text {obs }}$ and $\mathrm{A}$ will be restored, such that the Y-intercept is L times greater than the slope.

The effects of changes in $\mathrm{P}$ on the form of an isotope dilution plot are shown in Fig. 1, using simulated data. The concentration of labelled thymidine (L) was set a $1 \mathrm{nM}$, and $\mathrm{C}_{\max }$ at $20,000 \mathrm{DPM} \mathrm{ml}^{-1} \mathrm{~h}^{-1}$. $P$ remained constant $(8 \mathrm{nM})$ for cold thymidine additions of less than $5 \mathrm{nM}$. From 6 to $12 \mathrm{nM}, \mathrm{P}$ declined but was still nonzero. $\mathrm{P}$ became zero somewhere

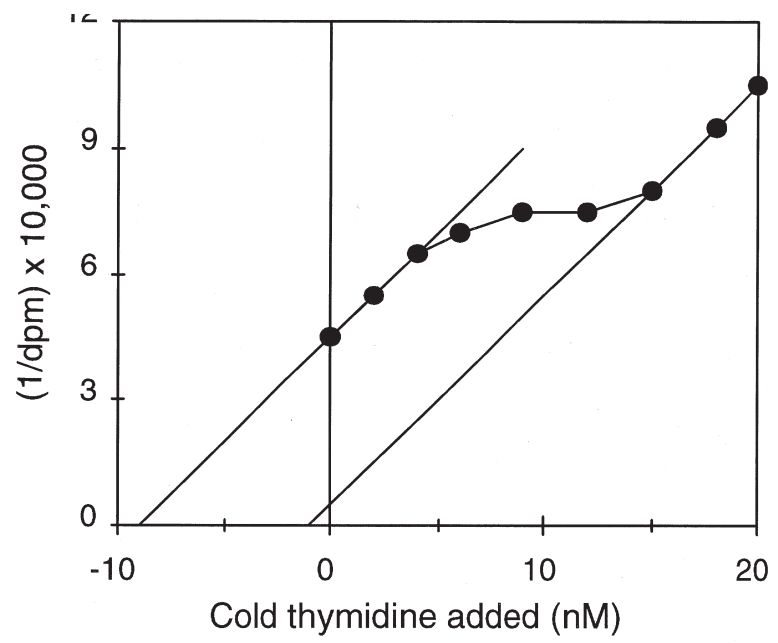

FIG. 1. - An illustration of the effects, on an isotope dilution analysis, of changes in participation of endogenously-produced thymidine, called here the endogenous 'pool size' (P) for simplicity, during DNA synthesis. Declining pool size between cold thymidine additions of 5 and $15 \mathrm{nM}$ gradually move the X-intercept $-(\mathrm{L}+\mathrm{P})$ toward $-\mathrm{L}$. between 12 and $15 \mathrm{nM}$ cold addition, so that the underlying slope once again became apparent, yielding the very high observations on the right of the graph. The points below $5 \mathrm{nM}$ extrapolate to an $\mathrm{X}$ intercept of $-9 \mathrm{nM}(-(\mathrm{L}+\mathrm{P}))$; the reestablished line through the upper points has an intercept of $-1 \mathrm{nM}$ (equal to L), since $\mathrm{P}$ had become zero. The data were designed to parallel the situation described in figure 2 of Bell (1986).

Ideally, one should watch for changes in isotope dilution plots, because inclusion of points from regions in which $\mathrm{P}$ is declining will result in underestimation of the degree of participation of labelled thymidine in DNA synthesis and overestimation of $\mathrm{C}_{\max }$. Unfortunately, however, it is difficult if not impossible in many cases to know whether $\mathrm{P}$ has varied. A plausible illustration of a result of this sort is shown in Fig. 2 (data in Table 1). The pool of endogenously produced thymidine declines over the range of 6 to $15 \mathrm{nM}$ cold thymidine added, such as might occur in the presence of gradual feedback inhibition of thymidylate synthetase, or if different subpopulations of bacteria were synthesizing thymidine at different rates (cf. Bird and Kalff, 1993). Even though the isotope dilution plot is perfectly linear, the endogenously produced thymidine pool and the DNA production rate would be overestimated by $60 \%$. The only guarantee that $\mathrm{P}$ has not been overestimated is if it is calculated to be zero. In other words, isotope dilution analysis is useful only to confirm that synthesis of natural TdR has been

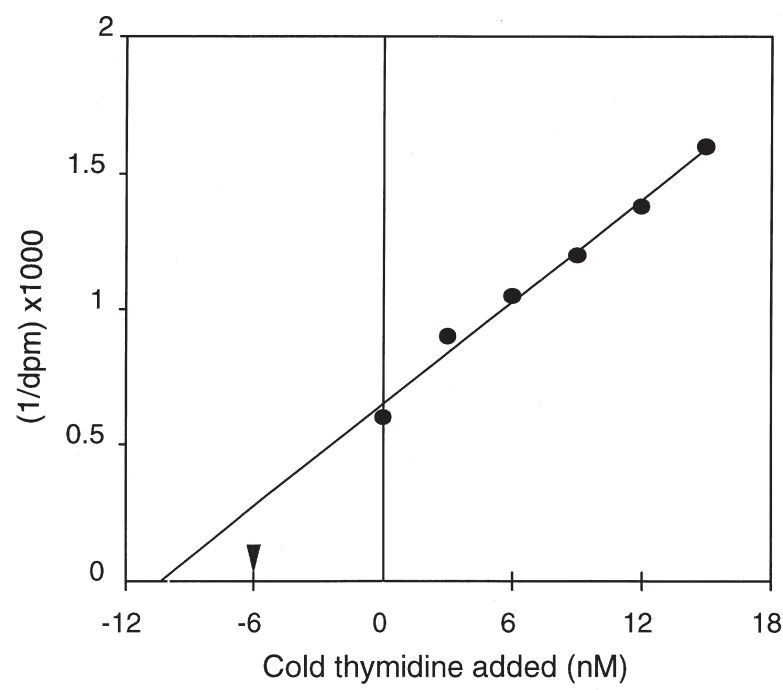

FIG. 2. - An illustration of the vulnerability of isotope dilution analysis to breakdown of the assumption of constant pool size P. $\mathrm{P}$ was constant at $5 \mathrm{nM}$ for only the first two points. Following that, it declined to 0 over the range of the remaining points. The X-intercept should have been at the arrow. 
TABLE 1. - Data used in Fig. 2 to illustrate the difficulty of detecting changes in endogenously-produced thymidine. Gradual reduction in the size of this 'pool' $(\mathrm{P})$ in response to changes in the concentration of cold thymidine added $(\mathrm{A})$ will alter the slope of the regression equation fit to the data. This bias can be very difficult to detect. Hot thymidine (L) is $1 \mathrm{nM}, \mathrm{C}_{\max }$ is $10,000 \mathrm{dpm}$.

\begin{tabular}{cccr}
\hline $\begin{array}{c}(\mathrm{A}) \\
\begin{array}{c}\text { Unlabelled } \\
\text { thymidine } \\
(\mathrm{nM})\end{array}\end{array}$ & $\begin{array}{c}(\mathrm{P}) \\
\text { Endogenous } \\
\text { thymidine } \\
(\mathrm{nM})\end{array}$ & $\begin{array}{c}\left(\mathrm{C}_{\mathrm{obs}}\right) \\
\text { Isotope } \\
\text { incorporation } \\
(\mathrm{dpm})\end{array}$ & $\begin{array}{r}\frac{10,000}{\mathrm{C}_{\mathrm{obs}}} \\
\left(\mathrm{dpm}^{-1}\right)\end{array}$ \\
\hline 0 & 5 & 1667 & 6 \\
3 & 5 & 1111 & 9 \\
6 & 3.5 & 952 & 10.5 \\
9 & 2 & 833 & 12 \\
12 & 0.8 & 725 & 16 \\
15 & 0 & 625 & \\
\hline
\end{tabular}

blocked. It is not trustworthy for the estimation of endogenous thymidine pool size.

In theory, variation in $\mathrm{P}$ could be detected by a series of dilution experiments at different levels of $\mathrm{L}$. Variation in P would then be detected as a discrepancy between observed and theoretical intercepts and/or slopes between regression lines. The precision attainable in isotope dilution experiments permits the detection of only large or sudden changes in pool size by this approach.

\section{ASSUMPTION TWO: \\ CONSTANT INCORPORATION RATE}

Perhaps the level of labelled thymidine added could be increased to try to ensure that endogenous thymidine production is completely inhibited. The latter has the drawbacks of increased cost and the real risk of altering $\mathrm{C}_{\text {max }}$

Forsdyke's (1968) procedure was a clever implementation of the substoichiometric isotope dilution principle (e.g. Yalow and Berson, 1960; Newsholme and Taylor, 1968; see review by Tölgyessi et al. 1972). It is founded on the supposition that equimolar concentrations of thymidine of different specific activities can be sampled after dilution. In other words, the analysis depends on the assumption that $\mathrm{C}_{\max }$, the rate of incorporation of thymidine into DNA, will remain constant at all levels of thymidine addition. Yet changes in $\mathrm{C}_{\max }$ can be shown to have occurred in the literature (Fig. 2 in Bell, 1986). By substituting the estimated value of $\mathrm{P}$ into equation (2), along with the observed values of $\mathrm{L}, \mathrm{A}$ and $\mathrm{C}_{\mathrm{obs}}$, values for $\mathrm{C}_{\max }$ can be calculated at each point (Table $2)$. These values can then be compared with the estimate of $\mathrm{C}_{\max }$ derived from regression analysis of
TABLE 2. - An example of possible stimulation of total incorporation of thymidine at higher levels of addition. These data were reconstructed from Fig. 2 of Bell (1986) by image analysis. A weighted linear regression analysis was used to derive estimates of $\mathrm{P}$, the endogenous pool $\left(0 \mathrm{nM}\right.$, i.e. no endogenous pool), and $\mathrm{C}_{\text {max }}$, the total thymidine incorporation rate $\left(7620 \mathrm{dpm} \cdot 5 \mathrm{ml}^{-1} \cdot \mathrm{h}^{-1}\right)$, using the lowest 6 observations. Estimates of $\mathrm{C}_{\max }$ at each point $\left(\mathrm{C}^{*}\right.$ ) were calculated from equation 2 using the given labelled thymidine concentration of $1 \mathrm{nM}$. $\mathrm{C}^{*}$ is expected to fall around 7620 ; the three greatest additions of cold thymidine resulted in substantially greater total thymidine incorporation.

\begin{tabular}{cccc}
\hline $\begin{array}{c}(\mathrm{A}) \\
\begin{array}{c}\text { Unlabelled } \\
\text { thymidine } \\
(\mathrm{nM})\end{array}\end{array}$ & $\begin{array}{c}\text { (10,000/ } \\
\left(\mathrm{dpm}^{-1}\right)\end{array}$ & $\begin{array}{c}\text { Mean } \mathrm{C}_{\text {obs }} \\
(\mathrm{dpm})\end{array}$ & $\begin{array}{c}\mathrm{C}^{*} \text { max } \\
(\mathrm{dpm})\end{array}$ \\
\hline & & & \\
\hline .3 & 2.0 & 4940 & 6587 \\
1.0 & 2.3 & 4370 & 8740 \\
1.5 & 3.1 & 3190 & 7975 \\
2.8 & 5.7 & 1760 & 6746 \\
4.3 & 7.5 & 1340 & 7146 \\
7.3 & 10.8 & 930 & 7749 \\
11.3 & 12.2 & 820 & 10113 \\
15.3 & 13 & 770 & 12576 \\
40 & 30 & 333 & 13653 \\
\hline
\end{tabular}

equation (2). In this case, if the assumptions of the analysis regarding constancy of $\mathrm{C}_{\max }$ had been met, it should be roughly $7600 \mathrm{DPM} \cdot \mathrm{h}^{-1} \cdot 5 \mathrm{ml}^{-1}(95 \%$ confidence limits $6760-8750$ ). $\mathrm{C}_{\max }$ lies within the confidence limits of this estimate for each of the first six observations. Past the sixth point, however, $\mathrm{C}_{\max }$ appears to have climbed rapidly so that by the last point, corresponding to an addition of $40 \mathrm{nM}$ cold thymidine, $\mathrm{C}_{\max }$ is almost double what it was at lesser thymidine levels. Therefore it appears that at higher concentrations of exogenously supplied thymidine, total heterotrophic incorporation of thymidine into macromolecules was stimulated in this lake. This is understandable in light of studies by Carman et al. (1988) and Brittain and Karl (1990) who showed that extensive catabolism of thymidine and recycling of the radioactive label can occur in natural samples.

\section{ASSUMPTION THREE: RADIOCHEMICAL PURITY}

The calculation of equation (1) assumes that L, the pool of labelled precursor, is pure thymidine or leucine, identical to the sources $\mathrm{A}$ and $\mathrm{P}$ that dilute it. Otherwise the dilution equation becomes:

$$
\mathrm{C}_{\text {obs }} / \mathrm{C}_{\max }=(\mathrm{I}+\mathrm{L}) /(\mathrm{I}+\mathrm{L}+\mathrm{P}+\mathrm{A})
$$

where $\mathrm{I}$ is the activity of any impurities that are incorporated, which are not diluted by added cold 


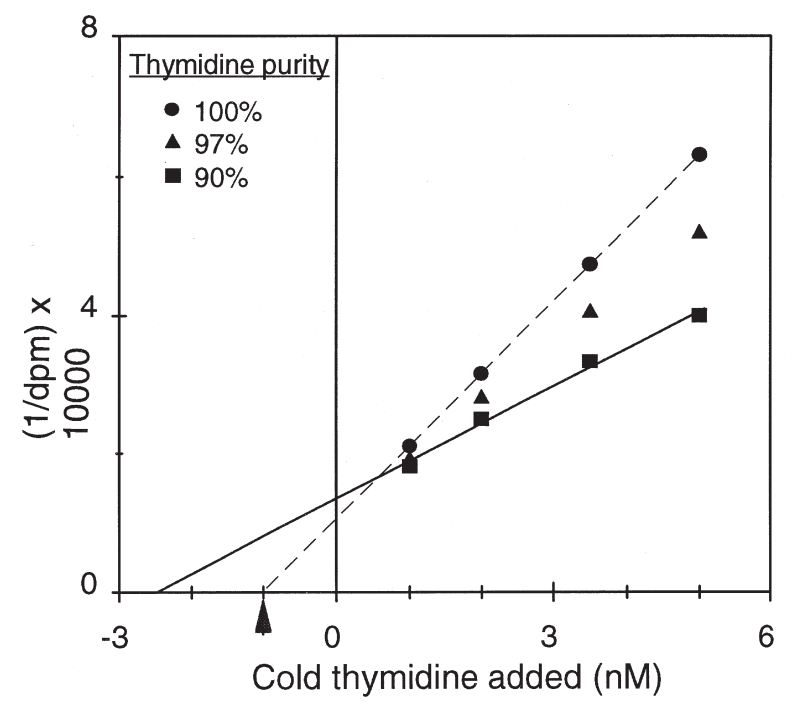

FIG. 3. - Even at low concentrations, labelled impurities have large effects on the estimated pool size, because they lower the slope of the isotope dilution plot. A plot with pure thymidine (1) gives the broken line when $\mathrm{L}$ is $1 \mathrm{nM}$ and $\mathrm{P}$ is 0 . When $10 \%$ of the incorporation is due to labelled breakdown products ( $\mathrm{n}$ - solid line) $\mathrm{P}$ appears to be $2.5 \mathrm{nM}$, in this example.

substrate. The effect of incorporation of labelled breakdown products on the dilution analysis is severe. Using the isotope dilution protocol suggested by Bell (1993) in the presence of 3\% impurities leads to a $30 \%$ overestimation of total thymidine incorporation rate, $5 \%$ impurities to $50 \%$ overestimation, $10 \%$ impurities to $110 \%$ overestimation (Fig. 3).

High-specific-activity tritiated compounds, like thymidine and leucine, are readily decomposed by primary and secondary radioactive effects (Evans, 1977). Improperly-stored thymidine can be $40 \%$ degraded in 6 months (Diab et al., 1970) and autoclaving can produce $50 \%$ thymine (Robarts and Zohary, 1993). Shelf-life can be extended by the addition of ethanol as a scavenger of hydroxyl radicals, although this adds the extra work of preliminary purification of the precursor by evaporation. Despite the addition of $2-10 \%$ ethanol, thymidine breakdown can be $2-4 \%$ per month. Hot thymidine purchased at the beginning of the field season will be unsuitable for isotope dilution experiments before the season ends. Thymidine is almost three times more reactive to hydroxyl radicals than is leucine, so that leucine has a considerably longer shelf-life. Ethanol can be used as a preservative for leucine as well; $0.1 \mathrm{~N}$ hydrochloric acid does not protect against secondary decomposition (Evans, 1977).

This sensitivity of the analysis to impurities can be turned around to provide a test of radiochemical purity. The method depends on an alternate form of isotope dilution that we might call 'hot dilution' where one gradually dilutes the cold pool with hot isotopes. This is in fact closer to the classical isotope dilution analysis, more specifically called "multiple substoichiometric isotope dilution" (Tölgyessy et al. 1972). The 'cold dilution' approach normal to microbial ecology outlined above (or "double substoichiometric isotope dilution"; Tölgyessy et al. 1972) involves dilution of hot and natural isotope with different amounts of cold isotope. The hot dilution analysis can be based on either a single or a double reciprocal transformation. When different amounts of radioactive thymidine are added to a sample, degree of participation can be calculated using the following double-reciprocal equation:

$$
1 / \mathrm{C}_{\mathrm{obs}}=1 / \mathrm{C}_{\max }+\left(\mathrm{P} / \mathrm{C}_{\max }\right) \cdot(1 / \mathrm{L})
$$

The independent variable is now the reciprocal of the concentration of added labelled thymidine. In this form, the rate of incorporation in the absence of dilution, is given by the reciprocal of the Y-intercept, and the pool size is given by the slope divided by the Y-intercept.

An alternative form of analysis of hot dilution experiments, which uses only a single reciprocal in its formulation, has been recommended for statistical reasons (Wilkinson, 1961). In this case, the model equation is:

$$
\mathrm{L} / \mathrm{C}_{\mathrm{obs}}=\mathrm{P} / \mathrm{C}_{\text {max }}+\left(1 / \mathrm{C}_{\max }\right) \cdot \mathrm{L}
$$

Despite the recommendation, I have found the double reciprocal equation (8) to give more accurate, more precise results than equation (9). In either form, the slope and intercept should be estimated using weighted least squares (see 'Statistical considerations' below).

When the labelled thymidine or leucine is not pure, the standard and the hot dilution approach will not give similar results. Figs. 4 and 5 show an extreme example of disagreement. The labelled solution of thymidine used for these experiments was a two-year old stock stored in sterile water at $4^{\circ} \mathrm{C}$. The incorporation of this product in lake water was not diminished at all by dilution with cold thymidine up to $10^{4}$ times more concentrated than the radioactive form (Fig. 4) Isotope dilution via the double-reciprocal method, on the other hand, showed an effective in situ pool of $34 \mathrm{nM}$ (Fig. 5). The constitution of this 'pool' was not determined, but it was clearly not thymidine. 


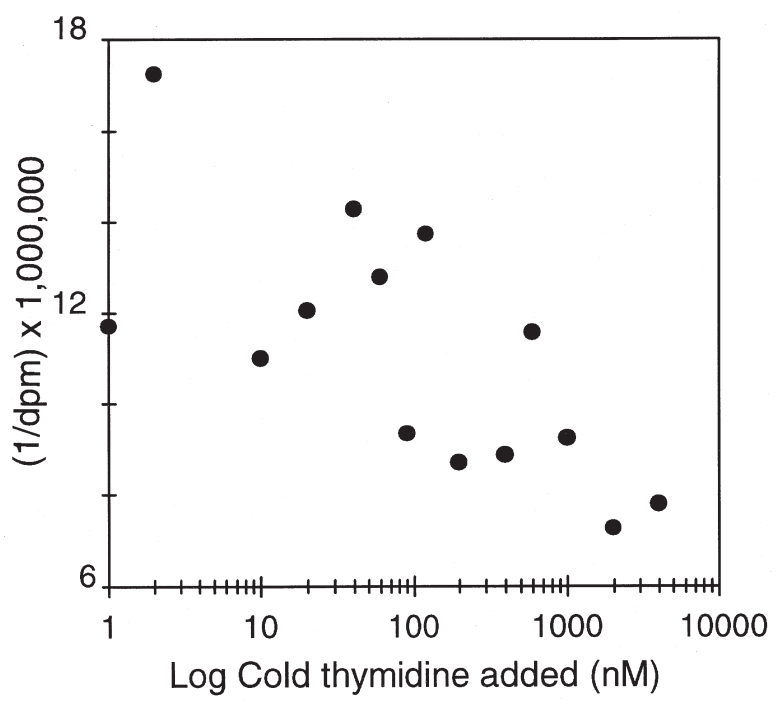

FIG. 4. -Isotope dilution plot using highly-labelled thymidine stock that had been stored too long. Incorporation rate of this product was not diluted by freshly prepared cold thymidine at any concentration - incorporation actually increased slightly at the highest cold additions. Incorporation rate was also highly variable. Compare to the alternative analysis of the same stock in Fig. 5.

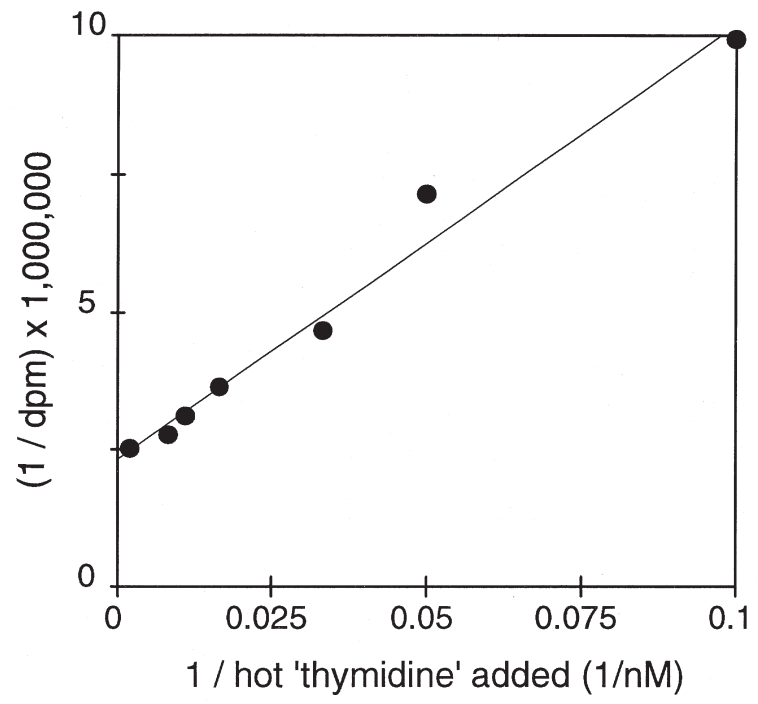

FIG. 5. - Hot dilution experiment using old thymidine stock. The slope of this line divided by the Y-intercept provides an estimate (34 nM) of the pool size of unknown substances diluting the incorporation of this product.

It is quite possible that claims in the literature about nonsaturability of thymidine or leucine incorporation, which are based on 'cold' dilution, are due to problems of radiochemical purity. Selfdecomposition might also lead to problems with the specificity of incorporation into target macromolecules (e.g. Wand et al., 1967) as well as variability of the factor to convert incorporation to cell production.
Diab et al. (1970) and Findlay et al. (1984) offer two methods for assessing the purity of labelled thymidine. The former used 2-dimensional thinlayer chromatography to detect labelled breakdown products. The latter tests thymidine purity by charcoal adsorption, which is suitable for the detection of tritiated water and any labelled products that do not adsorb to charcoal. Alternatively, purity can be checked by HPLC (Robarts and Zohary, 1993).

\section{ASSUMPTION 4: NO SEDIMENT OR COLLOIDAL ADSORPTION}

The use of isotope dilution experiments in sediments (Findlay, 1993) or in water containing substantial particulate or colloidal matter may be affected if there are nonspecific adsorptive losses. The difficulty arises because the values used for $\mathrm{L}$ and $\mathrm{A}$ in equation (2) are not correct under these circumstances. Avnimelech et al. (1983) indicate that, at low concentrations of most substances in sediments, the concentration of the solid phase (i.e., adsorbed thymidine) is a linear function of concentration of the dissolved phase. If a constant fraction $\mathrm{k}<1$ of added Tdr or Leu is available to the bacteria, then both $\mathrm{L}$ and $\mathrm{A}$ must be multiplied by $\mathrm{k}$ before dilution analysis. When the native sources of thymidine or leucine are all extracellular, then $\mathrm{P}$ must be multiplied by $\mathrm{k}$ as well, and the analysis is unaffected. However, Moriarty (1988) suggests that it is unlikely that extracellular dilution occurs in aquatic environments, even in sediments. He also suggests that major losses of added thymidine occur by sediment adsorption (Moriarty, 1984). The equation is:

$$
1 / \mathrm{C}_{\mathrm{obs}}=(\mathrm{kL}+\mathrm{P}) /\left(\mathrm{kL} \cdot \mathrm{C}_{\max }\right)+\left(1 /\left(\mathrm{kL} \cdot \mathrm{C}_{\max }\right)\right) \cdot \mathrm{A}
$$

where $\mathrm{k}$ is the fraction of thymidine or leucine available for incorporation. By comparison of this equation with equation (2) one can see that both the slope and the intercept are changed by adsorptive losses. Therefore neither can be used to calculate the maximum incorporation rate $\left(\mathrm{C}_{\max }\right)$; both eq. 4 and eq. 6 above will underestimate this rate. Furthermore, without knowledge of the availability of the substrate $(\mathrm{k})$, the true pool size $(\mathrm{P})$ cannot be estimated. As a result of adsorptive losses, therefore, $\mathrm{P}$ is overestimated. This is deadly to the standard approach. The bias in the estimation of the pool size (P) decreases as the concentration of labelled substrate (L) increases relative to $\mathrm{P}$, and as $\mathrm{k}$ approaches one. 
Therefore, one should have greater confidence in the analysis of the pool size $\mathrm{P}$ in sediment work the closer that the estimate of $\mathrm{P}$ is to zero, and the greater that the level of added label $\mathrm{L}$ is relative to $\mathrm{P}$.

When the proportion of thymidine adsorbed changes with the concentration added (for example, when the intercept of the linear adsorption curve is non-zero, as it may often be: cf. Avnimelech et al., 1983) then isotope dilution analysis is even further compromised. Non-proportional adsorption may explain the odd results of Tibbles and Harris (1996), in studies of antarctic soils, and Kaplan et al. (1992), in a study of stream bed sediments, where the apparent rate of dilution of added thymidine increased as more labelled or unlabelled thymidine was added. Adsorptive losses of leucine onto marine snow or colloids can strongly limit the amino acid's availability to bacteria (Schuster et al., 1998).

\section{STATISTICAL CONSIDERATIONS}

\section{Weighting}

Simple dilution with cold thymidine or leucine changes the mean rate of label incorporation but does not alter the relative variability (the coefficient of variation) among samples. This can be shown experimentally (unpublished data) and it is evident in most published graphs. As a result, the coefficient of variation of the transformed variable used in linear regression $\left(1 / \mathrm{C}_{\mathrm{obs}}\right)$ is also more or less constant, with a value more or less equal to the $\mathrm{CV}$ of the untransformed variable. The errors increase with the mean at each point and are not homogeneous as is necessary for maximum precision in estimating the X and Y intercepts (Draper and Smith, 1981, p. 110). Coefficients of variation in the literature range from $8 \%$ (Bell, 1986) to 49 to $60 \%$ (Meyer et al., 1987). It is therefore necessary to use weighted regression to account for heteroscedasticity, weighting each point by the reciprocal of its variance, whether using nonlinear or linear models.

Weighting the observations to control heteroscedasticity will not remove all statistical estimation problems, however. First, because the independent variable has been transformed to its reciprocal, the residual errors around the regression line will not in general be normally distributed, tending instead to be positively skewed. This means that confidence limit statements will be inaccurate. Second, use of the simple reciprocal of the Y-intercept will proba- bly underestimate the true mean value of the thymidine incorporation rate without added cold thymidine. This is because the mean of the reciprocal of a positive random variable (incorporated radioactivity, in this case) is always greater than the reciprocal of its mean (Chiang, 1966). In other words, ordinary least squares applied to reciprocals will estimate the harmonic, rather than the arithmetic mean of the untransformed values. For this reason, estimates of $\mathrm{P}$ and $\mathrm{C}_{\max }$ derived from the slope and intercept of the equation may also be inaccurate.

There are two solutions to the statistical problems of the current approach to isotope dilution analysis. The first retains the simplicity and familiarity of linear regressions, with a straightforward weighting technique. The second solution is to use weighted nonlinear least squares.

The first technique is simple to use. Theoretical justification can be found in Smith (1970). Each observation of $\mathrm{Y}$ (which is $1 / \mathrm{C}_{\mathrm{obs}}$ in this case) and $\mathrm{X}$ (which is $\mathrm{A}$ ) are weighted by $\mathrm{C}_{\text {obs }}$ itself. The weighting scheme works by counterbalancing the unequal effects of taking the reciprocals of points falling above and below the mean. An added advantage of the technique is that the distribution of the slope becomes more symmetrical, so that approximate confidence limits for $\mathrm{C}_{\text {max }}$ can obtained as the reciprocals of the confidence limits of the weighted slope.

The principal advantage of the weighting technique is that it puts great emphasis on the observations at low concentrations of added thymidine. The relationship in this region is the most appropriate for estimation of $\mathrm{C}_{\max }$ and $\mathrm{P}$, close to the concentration of thymidine $(\mathrm{L}+\mathrm{P})$ actually used in the measurement of production.

The second alternative is to analyse by weighted nonlinear regression. A good deal has been written in the aquatic literature extolling the virtues of nonlinear regression analysis. With appropriate precautions, linearisable relations may be just as well analysed by linear as by nonlinear fitting techniques. Nonlinear regression may not be as stable as linear techniques, and diagnostic assessment of the result is more difficult. It is not easy to visually detect changes in the parameters of the equation $\left(\mathrm{P}, \mathrm{C}_{\max }\right)$ that are more evident with linear regression plots (Fig. 1). Furthermore, parameter-effects nonlinearity can be significant for the isotope dilution formulation (Bates and Watts, 1980), the distribution of the statistics can be markedly non-normal (skewed and kurtotic), the statistic itself biased and the asymptotic confidence limits quite inacurrate. 


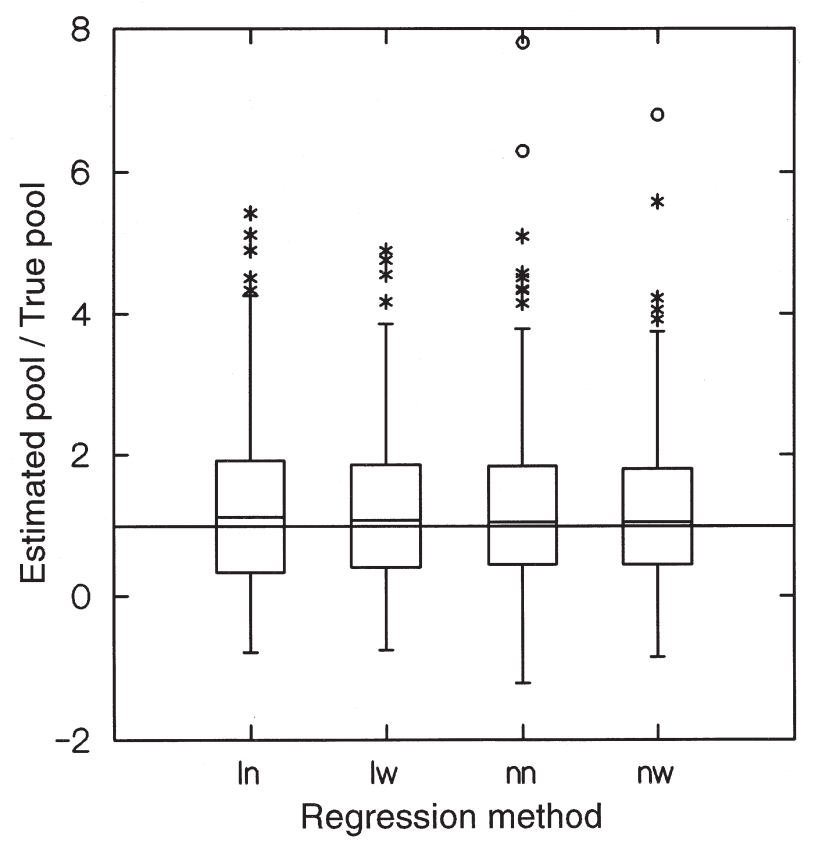

FIG. 6. - Boxplots of the distribution of the ratio of the pool size P, estimated by 4 different regression methods, to its true value, in 1000 simulations. The ratio should be 1 on average. The observed medians are given by the midlines in the boxes. Methods were linear nonweighted (ln), linear weighted (lw), nonlinear nonweighted (nn) and nonlinear weighted regression (nw).

But the question of linear versus nonlinear techniques is a red herring. Simulations indicate that weighting is the most important consideration in isotope dilution analysis, the linear and nonlinear approaches giving otherwise almost identical results (Fig. 6). Bliss and James (1966) describe methods for maximum likelihood calculation of the unbiased confidence limits of nonlinear regression estimates.

\section{Calculation of 'degree of participation'}

In the standard approach to isotope dilution, the rate of incorporation of thymidine from all sources is calculated based on the 'degree of participation' L/ ( L + P + A) (DP: Moriarty and Pollard, 1981; Chrzanowski, 1988), or the 'effective pool' $\mathrm{L}+\mathrm{P}$ (EP: Findlay et al., 1984; Hudson et al., 1990). As noted above, these are calculated based on the Xintercept of the linear equation. The calculation is:

$$
\begin{aligned}
\mathrm{I} & =\mathrm{C}_{0} /(\operatorname{vol} \times \text { inc } \times \mathrm{SA} \times \mathrm{DP}) \\
& =\mathrm{C}_{0} \times \mathrm{EP} /(\operatorname{vol} \times \text { inc } \times \mathrm{SA} \times \mathrm{L})
\end{aligned}
$$

where $\mathrm{I}$ is the estimated rate of thymidine (leucine) incorporation per unit volume (or area) per unit time (mol per $\mathrm{L}$ or per $\mathrm{cm}^{-2}$, per unit time), $\mathrm{C}_{0}$ is the radioactivity incorporated in the sample (disintegra- tions per minute), vol is the volume (or area) of the sample $\left(\mathrm{L}\right.$ or $\left.\mathrm{cm}^{-2}\right)$, inc the incubation time (hours, for example), SA is the specific activity of the added labelled thymidine (disintegrations per minute per $\mathrm{mol}$ ), and DP, EP and L are as above. An alternative calculation is:

$$
\mathrm{I}=\mathrm{C}_{0} /(\operatorname{vol} \times \text { inc } \mathrm{x} \text { SA } \times \mathrm{DF})
$$

where $\mathrm{C}_{0}$, vol, inc and SA are as above and DF is the diluting factor $\mathrm{C}_{\mathrm{obs}} / \mathrm{C}_{\max }$ for $\mathrm{C}_{\text {obs }}$ with no cold thymidine added in the dilution experiment, equivalent conceptually to the degree of participation calculated as above.

Despite the conceptual equivalence, the two approaches vary markedly in their precision. Pool size estimates are quite uncertain relative to estimation of $\mathrm{C}_{\max }$, the incorporation rate of thymidine from all sources. Use of the diluting factor DF in place of the degree of participation DP in the calculation of I typically reduces the uncertainty in the estimate of I by greater than $80 \%$. An example of the difference in precision is shown in Fig. 7, which is based on 1000 simulations of a dilution experiment wherein $\mathrm{L}$ was $3 \mathrm{nM}$, P was $2 \mathrm{nM}$, A was $3,6,10$ and $15 \mathrm{nM}, \mathrm{C}_{\max }$ was $10,000 \mathrm{DPM}$ and the coefficient of variation of incorporation rate was $15 \%$, a plausible environmental situation. The plot shows the frequency distribution of the ratios of $\mathrm{C}_{\max }$ and $\mathrm{P}$, estimated by ordinary least squares, to their true values. A similar increase in precision can be obtained by calculating DF depending on $\mathrm{C}_{\text {max }}$ rather than $\mathrm{P}$ in the nonlinear regression setting.

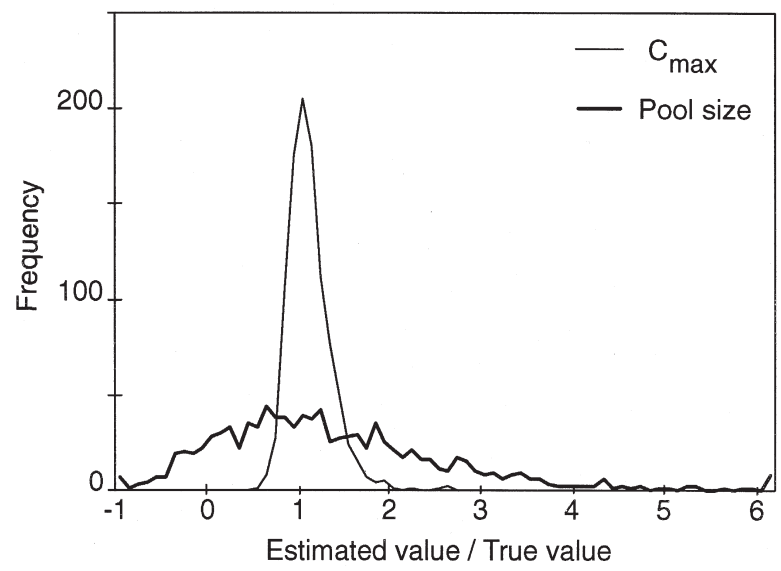

FIG. 7. - The frequency distribution of the ratios of estimates of the true bacterial incorporation rate $\left(\mathrm{C}_{\mathrm{max}}\right)$ and the unlabelled pool size (P) to their true values, in 1000 simulations of a linear nonweighted isotope dilution analysis. Estimation of $\mathrm{C}_{\max }$, using the slope of the isotope dilution equation, is considerably more accurate and precise than estimation of $\mathrm{P}$, which is based on the $\mathrm{X}$-intercept. 
A surprising discovery was that the 'hot dilution' approach was as accurate and more precise than the cold dilution analysis. Error in the estimation of $\mathrm{C}_{\max }$ via weighted hot dilution experiments was $20 \%$ lower than that for weighted cold dilution. However, the extra cost due to extra isotope usage in hot dilution is not worth the increased precision, which can be more economically achieved via a cold dilution analysis with a greater number of replicates.

\section{CONCLUSIONS}

The analytical structure of the isotope dilution analysis now used in microbial ecology was originally developed in order to estimate the extracellular pools of nucleosides in serum and in culture media used for growing lymphocytes (Forsdyke, 1968). The principle is simple and powerful, when the necessary conditions are met. Its adoption for the measurement of both extracellular and changing intracellular pools in environmental samples must be approached with caution and an awareness of the potential for error. Variation in the intracellular synthesis of thymidine and leucine will lead to an overestimation of P. Too much extracellular thymidine can increase total macromolecular incorporation rate. Labelled precursors that are not absolutely fresh or repurified will lead to overestimation of $\mathrm{P}$ as well as to nonspecific incorporation. Sediment adsorption can lead to overestimation of $\mathrm{P} . \mathrm{C}_{\max }$ alone should be used for the calculation of the dilution factor in the sediments.

The standard statistical approach can be improved considerably by weighting, and especially by depending on $\mathrm{C}_{\max }$ rather than $\mathrm{P}$ in the calculation of overall incorporation rate. The best statistical methods will not make up for violations of the fundamental assumptions of the analysis. In light of the strong potential for error introduced by non-constant $\mathrm{P}$ and $\mathrm{C}_{\max }$, investigators interested in the most accurate results must be prepared to recognize the symptoms of these changes.

On the basis of this examination, and what has passed before in the debate over thymidine and leucine assays and the accuracy of the theoretical conversion factors on which they depend, it is evident that these assays are overly susceptible to breakdown of assumptions. Despite the extra expense and effort, there is no real substitute for experimental, empirical determination of the conversion factor from incorporation to growth rate (e.g. Kirchman and Ducklow, 1993), although these incubations are subject to another set of uncertainties (e.g. Chrzanowski et al., 1993). Isotope dilution analysis remains the only alternative in the sediments, however, where community growth rate determination by incubation is not yet feasible.

\section{ACKNOWLEDGEMENTS}

This work was supported by a Natural Sciences and Engineering Research Council of Canada operating grant, and benefited from discussions with D. Karl, C. Winn and E. Laws (University of Hawaii) and comments of a referee. A contribution to the Groupe de recherche en écologie aquatique de l'UQAM (GREAU) and the Groupe de recherche interuniversitaire en limnologie (GRIL). I also acknowledge the generosity of the Dirección General de Enseñanza Superior, Ministerio de Educación y Cultura of Spain for support during its writing.

\section{REFERENCES}

Avnimelech, Y., M. Yamamoto and R.G. Menzel. - 1983. Evaluating the release of soluble components from sediment. J. Environ. Qual., 12: 86-91.

Bates, D.M. and D.G. Watts. - 1980. Relative curvature measures of nonlinearity. J.R. Statist. Soc., Ser. B 42: 1-25.

Bell, R.T. - 1986. Further verification of the isotope dilution approach for estimating the degree of participation of $\left[{ }^{3} \mathrm{H}\right]$ thymidine in DNA synthesis in studies of aquatic bacterial production. Appl. Environ. Microbiol., 52: 1212-1214.

Bell, R.T. - 1993. Estimating production of heterotrophic bacterioplankton via incorporation of tritiated thymidine. In: P.F. Kemp, B.F. Sherr, E.B. Sherr and J.J. Cole (eds.): Handbook of methods in aquatic microbial ecology, pp. 495-503.. Lewis Publishers, Boca Raton.

Bird, D.F. and J. Kalff. - 1993. Protozoan grazing and size-activity structure in limnetic bacterial communities. Can. J. Fish. Aquat. Sci., 50: 370-380.

Bliss, C.I. and A.T. James. - 1966. Fitting the rectangular hyperbola. Biometrics, 22: 573-602.

Brittain, A.M. and D.M. Karl. - 1990. Catabolism of tritiated thymidine by aquatic microbial communities and incorporation of tritium into RNA and protein. Appl. Environ. Microbiol., 56: 1245-1254.

Carman, K.R., F.C. Dobbs and J.B. Guckert. - 1988. Consequences of thymidine catabolism for estimates of bacterial production: an example from a coastal marine sediment. Limnol. Oceanog., 33: $1595-1606$.

Chiang, C.L. -1966 . On the expectation of the reciprocal of a random variable. Amer. Stat., 20: 28.

Chróst, R.J. - 1990. Application of the isotope dilution principle to the determination of substrate incorporation by aquatic bacteria. Arch. Hydrobiol. Beih. Ergebn. Limnol., 34: 111-117.

Chrzanowski, T.H. - 1988. Consequences of accounting for isotopic dilution in thymidine incorporation assays. Appl. Environ. Microbiol., 54: 1868-1870.

Chrzanowski, T.H., K. Simek, R.H. Sada and S. Williams. - 1993. Estimates of baxcterial growth rate constants from thymidine incorporation and variable conversion factors. Microb. Ecol. 25: 121-130.

Diab, I.M. and L.R. Roth. - 1970. Autoradiographic differentiation of free, bound, pure, and impure thymidine- ${ }^{3} \mathrm{H}$. Stain Technol., 45: 285-291. 
Draper, N.R. and H. Smith. - 1981. Applied regression analysis. John Wiley \& Sons, Toronto.

Evans, E.A. - 1977. Storage and stability of radiotracer compounds. In: E.A. Evans and M. Muramatsu (eds.): Radiotracer techniques and applications, vol. 1, pp. 237-340. Marcel Dekker Inc., New York.

Findlay, S. - 1993. Thymidine incorporation into DNA as an estimate of sediment bacterial production. In: P.F. Kemp, B.F. Sherr, E.B. Sherr and J.J. Cole (eds.): Handbook of methods in aquatic microbial ecology, pp. 505-508. Lewis Publishers, Boca Raton.

Findlay, S.E.G., J.L. Meyer and R.T. Edwards. - 1984. Measuring bacterial production via rate of incorporation of $\left[{ }^{3} \mathrm{H}\right]$ thymidine into DNA. J. Microb. Meth., 2: 57-72.

Forsdyke, D.R. - 1968. Studies of the incorporation of $\left(5-{ }^{3} \mathrm{H}\right)$ uridine during activation and transformation of lymphocytes induced by phytohaemagglutinin. Biochem. J., 107: 197-205.

Fuhrman, J.A. and F. Azam. - 1982. Thymidine incorporation as a measure of heterotrophic bacterial production in marine surface waters: evaluation and field results. Mar. Biol., 66: 109-120.

Hudson, J.J., J.C. Roff and B.K. Burnison. - 1990. Measuring epilithic bacterial production in streams. Can. J. Fish. Aquat. Sci., 47: 1813-1820.

Jorgensen, N.O.G. - 1992. Incorporation of $\left[{ }^{3} \mathrm{H}\right]$ valine into protein of freshwater bacteria: uptake kinetics and intracellular isotope dilution. Appl. Environ. Microbiol., 58: 3638-3646.

Kaplan, L.A., T.L. Bott and J.L. Bielicki. - 1992. Assessment of $\left[{ }^{3} \mathrm{H}\right]$ thymidine incorporation into DNA as a method to determine bacterial productivity in stream bed sediments. Appl. Environ. Microbiol., 58: 3614-3621.

Kirchman, D.L. and H.W. Ducklow. - 1993. Estimating conversion factors for the thymidine and leucine methods for measuring bacterial production. In: P.F. Kemp, B.F. Sherr, E.B. Sherr and J.J. Cole (eds.): Handbook of methods in aquatic microbial ecology, pp. 513-517. Lewis Publishers, Boca Raton.

Kirchman, D.L., E. K'nees and R. Hodson. - 1985. Leucine incorporation and its potential as a measure of protein synthesis by bacteria in natural aquatic systems. Appl. Environ. Microbiol., 49: 599-607.

Meyer, J.L., R.T. Edwards and R. Risley. - 1987. Bacterial growth on dissolved organic carbon from a blackwater river. Microb. Ecol., 13: 13-29.

Moriarty, D.J.W. - 1984. Measurements of bacterial growth rates in some marine systems using the incorporation of tritiated thymidine into DNA. In: J.E. Hobbie and P.J. LeB. Williams (eds.): Heterotrophic activity in the sea, pp. 217-231. Plenum Press, New York.
Moriarty, D.J.W. - 1986. Measurement of bacterial growth rates in aquatic systems from rates of nucleic acid synthesis. $A d v$. Microb. Ecol., 1: 245-292.

Moriarty, D.J.W. - 1988. Accurate conversion factors for calculating bacterial growth rates from thymidine incorporation into DNA: elusive or illusive? Arch. Hydrobiol. Beih. Ergebn. Limnol., 31: 211-217.

Moriarty, D.J.W. and P.C. Pollard. - 1981. DNA synthesis as a measure of bacterial productivity in seagrass sediments. Mar. Ecol. Prog. Ser., 5: 151-156.

Newsholme, E.A. and K. Taylor. - 1968. A new principle for the assay of metabolites involving the combined effects of isotope dilution and enzymatic catalysis. Biochim. Biophys. Acta, 158: 11-24.

Riemann, B., J. Fuhrman and F. Azam. - 1982. Bacterial secondary production in freshwater measured by ${ }^{3} \mathrm{H}$-thymidine incorporation method. Microb. Ecol., 8: 101-114.

Robarts, R.D. and T. Zohary. - 1993. Fact or fiction - bacterial growth rates and production as determined by [methyl- $\left.{ }^{3} \mathrm{H}\right]-$ thymidine? Adv. Microb. Ecol., 13: 371-425.

Schuster, S., J.M Arrieta and G.J. Herndl. - 1998. Adsorption of dissolved free amino acids on colloidal DOM enhances colloidal DOM utilization but reduces amino acid uptake by orders of magnitude in marine bacterioplankton. Mar. Ecol. Prog. Ser., 166: 99-108.

Simon, M. and F. Azam. - 1989. Protein content and protein synthesis rates of planktonic marine bacteria. Mar. Ecol. Prog. Ser., 51: 201-213.

Smith, J.H. - 1970. Weighting for transformations of the dependent variable. Amer. Statist., 24(3): 16-20.

Tölgyessy, J., T. Braun and M. Kyrš. - 1972. Isotope dilution analysis. Pergamon Press, Oxford.

Tibbles, B.J. and J.M. Harris. - 1996. Use of radiolabelled thymidine and leucine to estimate bacterial production in soils from continental Antarctica. Appl. Environ. Microbiol., 62: 694-701.

Van Looij, A. and B. Riemann. - 1993. Measurements of bacterial production in coastal marine environments using leucine: application of a kinetic approach to correct for isotope dilution. Mar. Ecol. Prog. Ser., 102: 97-104.

Wand, M., E. Zeuthen and E.A. Evans. - 1967. Tritiated thymidine: effect of decomposition by self-radiolysis on specificity as a tracer for DNA synthesis. Science, 157: 436-438.

Wilkinson, G.N. - 1961. Statistical estimation in enzyme kinetics. Biochem. J., 80: 324-332.

Yalow, R.S. and S.A. Berson. - 1960. Immunoassay of endogenous plasma insulin in man. J. Clin. Invest., 39: 1157-1175.

Scient. ed.: C. Pedrós-Alió 